16 | InterAção

\title{
O GENOCÍDIO E O FIM DAS TEORIAS DAS RELAÇÕES INTERNACIONAIS
}

\author{
Leonardo Augusto Peres ${ }^{1}$
}

\section{Resumo}

O genocídio é um dos crimes mais atrozes contra a humanidade, mas sua compreensão e estudo ainda representam um campo de pesquisa muito limitado, o que dificulta sua prevenção e erradicação. Este artigo propõe, portanto, que as Relações Internacionais têm uma contribuição significativa a dar ao nascente campo de Estudos de Genocídio. Insere-se, assim, o conceito de genocídio no debate sobre o "fim da teoria" nas Relações Internacionais, perguntando-se se aquele é mais adequado a um estudo através de Teorias Gerais ou de teorias de médio alcance advindas de testes de hipóteses. Concluise, através de argumentos substantivos, normativos e metodológicos, que, no estágio atual das pesquisas sobre o genocídio, é mais interessante fazer estudos através de Teorias, para que, entre outros, se revelem as variáveis, indicadores e valores necessários aos testes de hipótese.

Palavras-chave: Genocídio. Teoria das Relações Internacionais. Epistemologia das Relações Internacionais.

\begin{abstract}
Genocide is one of the most heinous crimes against humanity, but the understanding of the phenomenon, as well as the field of study about this object, are still very restricted, which makes it difficult to present and eradicate the issue. This article argues, then, that the discipline of International Relations has a significant contribution to give to Genocide Studies. The concept of genocide, therefore, is introduced to the debate about the "end of theory" in International Relations, questioning if this object could be most adequately studied through general Theories or through middle range theories originated from testing hypotheses. The conclusion of this work, achieved through substantive, normative and methodological arguments, is that, given the present stage of research on genocide, it is more interesting to carry out investigations using general Theories, so that, among others, variables, indicators, and values necessary for hypotheses testing can be revealed.
\end{abstract}

${ }^{1}$ E-mail: Iperes15@gmail.com; CV Lattes: 〈http://lattes.cnpq.br/6331758831953468>. 
17 | InterAção

Key-words: Genocide. International Relations Theory. International Relations Epistemology.

\section{INTRODUÇÃO}

Presenciar-se-á, contemporaneamente, o ocaso das Teorias de Relações Internacionais? Este é o debate proposto por um número especial do European Journal of International Relations do ano de 2013. Os editores Dunne, Hansen e Wight (2013) propõem, portanto, um debate com a temática - e baseado na indagação sobre - o "fim das Teorias". De um lado, posicionam-se autores cuja visão é a de que grandes Teorias Gerais da disciplina podem - e devem - se desenvolver; teorias com aplicação universal e que podem ajudar a elucidar todo qualquer fenômeno que ocorra no sistema internacional. Opõem-se a eles estudiosos que julgam que tal forma de teorização não é possível, propondo assim o desenvolvimento da disciplina de Relações Internacionais através de sucessivas pesquisas de teste de hipótese, que podem levar no máximo a teorias de médio alcance.

Este artigo pretende, pois, situar nesse debate o conceito de "genocídio". Levando-se em consideração que as teorias podem ser compreendidas, ainda que de maneira simplificada, como um conjunto organizado e coeso de conceitos, acredita-se que pensar acerca de um conceito específico, ainda que não esgote as possibilidades de análise, pode auxiliar na compreensão da discussão teórica e da construção de teorias na disciplina. Pergunta-se, portanto, se o conceito de genocídio adequa-se a uma Teoria Geral das Relações Internacionais ou se seu estudo pode ser realizado através de pesquisas que testam hipóteses acerca desse fenômeno, levando, talvez, à elaboração de uma teoria de médio alcance, ou seja, 
18 | InterAção

uma teoria específica de genocídios, que explicaria este fenômeno, mas nada mais nas relações internacionais.

A fim de que se chegue a uma conclusão sobre essa indagação, a argumentação deste artigo está dividida em três partes principais. Em primeiro lugar, expor-se-á o debate acerca do fim das teorias em Relações Internacionais, com base em artigos da supracitada edição especial do European Journal of International Relations. Posteriormente, discutir-se-á o conceito de genocídio, com ênfase especial à ponderação sobre sua aplicação às Relações Internacionais - os casos de genocídio são concernentes à disciplina, ou são matéria de estudos do Direito e da Ciência Política? A terceira parte sintetizará as duas anteriores e procurará responder a questão fundamental deste trabalho, ou seja, buscará concluir, mesmo que não definitivamente, se o conceito de genocídio pode se incluir em uma grande Teoria das Relações Internacionais ou se a pesquisa que tem esse crime contra a humanidade como tema deve ser levada a cabo através de teorias mais restritas, mas que podem levar a uma maior profundidade e especificidade.

Este trabalho procura, portanto, embasar uma discussão mais aprofundada sobre o genocídio no campo das Relações Internacionais. Esse debate justifica-se, pois, mesmo após tantos horrores testemunhados pela humanidade, especialmente a partir da segunda metade do século $X X$, casos de genocídio seguem ocorrendo sem a devida atenção ou a resposta adequada tanto por parte dos atores internacionais quanto oriunda da comunidade científica de Relações Internacionais. 
19 | InterAção

\section{FIM DAS TEORIAS DE RELAÇÕES INTERNACIONAIS?}

Tentando, desde seu surgimento, se estabelecer como disciplina acadêmica, as Relações Internacionais sempre focaram sua discussão e desenvolvimento científico através de "grandes debates", mesmo que seja difícil identificar, na prática, diálogos de fato entre os teóricos liberais e realistas da primeira metade do século XX, por exemplo. De qualquer forma, a autoimagem que as Relações Internacionais têm de sua evolução enquanto ciência baseia-se fortemente nesses debates e em suas sínteses, quando plausíveis.

É possível, porém, que essa forma de teorizar as relações internacionais esteja mudando, ou até mesmo acabando. É o diagnóstico que fazem Dunne, Hansen e Wight (2013), que, no papel de editores do European Journal of International Relations, identificam uma transformação nos artigos submetidos ao periódico: tanto trabalhos com teor de debate inter-teórico quanto submissões de artigos puramente teóricos, segundo os autores, diminuíram. Seriam essas, pois, evidências de que as guerras paradigmáticas estariam dando lugar a uma paz teórica embasada no "pluralismo". Ainda de acordo com os editores, o que isso poderia revelar é que a disciplina de Relações Internacionais finalmente está madura, aceitando a diversidade teórica.

Essas observações concretas dos autores evidenciariam que as Relações Internacionais cessaram de majoritariamente produzir conhecimento teórico para dar lugar à produção de conhecimento "substantivo". Os debates entre as correntes teóricas arrefeceram, e agora o campo estaria frente a um período de teste de teorias (DUNNE, HANSEN \& WIGHT, 2013). Mas se o desenvolvimento teórico da disciplina notadamente sempre ocorreu através dos debates teóricos e tais diálogos arrefeceram a ponto de dar lugar ao mero teste de teorias já existentes, isso significaria que a teorização das Relações Internacionais chegou 
$20 \mid$ InterAção

ao fim? E, se for esse o caso, decorre que testemunha-se também o ocaso do desenvolvimento da disciplina enquanto ciência, incutindo uma crise ainda mais grave nesse campo de estudos?

Pelo menos alguns dos estudiosos chamados a escrever no número especial do European Journal of International Relations sobre o "fim das teorias" respondem negativamente a essas questões (MEARSHEIMER \& WALT, 2013; BENNETT, 2013; EPSTEIN, 2013). O “fim das teorias" representaria, de fato, um fim da estruturação da forma de teorizar as relações internacionais através de "grandes debates". Mas isso se traduz em uma mudança na teorização, não em seu ocaso.

Assim, o século XXI inicia, para a disciplina de Relações Internacionais, paradoxalmente, com um novo debate: como proceder à teorização em um novo contexto de pluralismo teórico, ou seja, em um cenário acadêmico no qual o debate entre as próprias teorias não tem, talvez, mais o mesmo valor que anteriormente? O que se observa, portanto, com esse questionamento é uma alteração do nível do debate, da teoria para a metateoria. Duas vertentes principais como alternativas de posicionamentos nesse novo debate metateórico.

Os dois posicionamentos principais são os de que o desenvolvimento teórico das Relações Internacionais deve se dar de através de: (i) teorização pura, ou seja, através da busca por Teorias Gerais (cujo ápice seria a elaboração de uma Grande Teoria de Relações Internacionais), de aplicação universal; ou (ii), testes de hipóteses, ou seja, do uso de teorias de médio alcance acerca dos mecanismos causais de fenômenos particulares das relações internacionais.

No primeiro grupo inserem-se Mearsheimer e Walt (2013), para quem as Teorias são a base das Relações Internacionais. Segundo eles, porém, essa base tem sido crescentemente ignorada na disciplina, de modo a dar espaço aos testes de hipóteses, considerados por eles “simplistas". As Teorias, portanto, seriam 
$21 \mid$ InterAção

indispensáveis não apenas porque são necessárias para guiar qualquer pesquisa que se faça - mesmo, por conseguinte, os testes de hipóteses - mas também por fornecerem um framework geral que explica um grande número de casos. Ademais, os autores elencam outras virtudes das Teorias: têm capacidade de revolucionar pensamentos; possibilitam previsões; diagnosticam problemas políticos e auxiliam nas decisões, além de avaliar seus resultados; informam acerca de fatos passados; ajudam na análise de fatos esparsos; são também indispensáveis para a construção de testes empíricos válidos (MEARSHEIMER \& WALT, 2013).

Bennett (2013), porém, situa-se no outro polo do debate, e critica essa visão extremamente teoricista que possuem os autores supracitados. Segundo ele, toda a discussão sobre a filosofia da ciência está atrasada no campo das Relações Internacionais. As Teorias seriam baseadas em hard-core assumptions, que não poderiam ser falseadas. Desta feita, a sugestão de que a disciplina deve se organizar em torno das Grandes Teorias é errônea, pois tais Teorias não podem dialogar entre si. Não seria possível, em conclusão, de acordo com o autor, atribuir poder explicativo às próprias Teorias, mas apenas aos mecanismos causais.

Há ainda críticas mais contundentes à teorização na disciplina, como aquela de Lake (2011), para o qual os "ismos" - ou seja, as Teorias Gerais - são "malvados". Segundo o autor, os debates teóricos nas Relações Internacionais dividem os estudiosos em "séquitos" que travam batalhas teológicas entre si, não contribuindo para a melhor compreensão dos fenômenos internacionais. As Teorias, ademais, sofreriam de cinco "patologias" que as tornariam inadequadas à pesquisa científica na disciplina: (i) a reificação das tradições de pesquisa, que levaria os estudiosos a tratarem as Teorias como entidades coesas com poder explicativo independente; (ii) a recompensa por extremismos, que leva à busca 
22 InterAção

por formas puras e canônicas das Teorias; (iii) a confusão entre "tradições de pesquisa" e Teorias, que leva à aceitação de explicações incompletas dos fenômenos, ao se considerar geral uma explicação particular; (iv) a limitação dos objetos de estudo apenas àqueles que a tradição das Teorias consegue explicar adequadamente; e (v), a disputa entre os estudiosos para que sua Teoria seja $o$ paradigma científico, aclamado universalmente e considerado possuir aplicação a todos os fenômenos do sistema internacional (LAKE, 2011).

Um contraponto ao diagnóstico das patologias da Teoria é feito por Nau (2011). Acerca da última patologia descrita por Lake (2011), o autor defende que a rejeição de uma teoria holística pode significar ignorar uma oportunidade de se enxergar o "todo" das relações internacionais. Ainda segundo Nau (2011), esses cinco problemas não existem, e o mais produtivo para as Relações Internacionais é mesmo que os "ismos" se confrontem, ou seja, que os debates teóricos sigam ocorrendo. $\mathrm{O}$ autor julga que o conhecimento social é evolucionário e endógeno, e, portanto o diálogo que Lake (2011) rotula como "teológico" é, de fato, funcional, tendo em vista que o desenvolvimento científico depende da contestação, tornando o consenso prejudicial.

Contrariamente a essas críticas, Lake (2011) conclui que os teóricos perdem seu tempo debatendo pressupostos e não pesquisam o mundo, atravancando a construção do conhecimento substantivo acerca de seu objeto de estudos principal: a realidade complexa das relações internacionais. Para o autor, portanto, o estudo da disciplina deve focar-se nos "problemas" e não nas abordagens teóricas. Decorre disso que também se deve aceitar a parcialidade e, consequentemente, adotar-se o ecletismo analítico. Lake (2011) ainda conclui, mais uma vez opondo-se a Nau (2011), para quem as lutas "teológicas" são produtivas, que o conhecimento não é construído através delas. 
23 | InterAção

De maneira semelhante, Bennett (2013) advoga que se estudem as Relações Internacionais através de teorias de médio alcance, que revelem as formas pelas quais os mecanismos causais interagem em determinadas condições a fim de que se gerem resultados específicos. A grande vantagem desse tipo de teorização, para o autor, é que sofre menos do problema de indeterminação. Os mecanismos causais, portanto, segundo ele, poderiam determinar conclusões com mais precisão, sem a necessidade de presunções - argumentos "as if" - por serem menos sucintos do que leis, que, para terem validade mais universal, acabam por ser mais indeterminadas. Destarte, o ideal das Relações Internacionais, para Bennett (2013) e para os demais autores que adotam essa corrente de pensamento, não deveria ser a tentativa de se alcançar uma grande Teoria Geral, mas teorias que determinem variáveis e hipóteses de mecanismos causais, e assim possam fornecer generalizações sobre como e sob quais condições as variáveis independentes comportam-se em situações específicas a fim de que se produzam os efeitos sobre as variáveis dependentes.

Críticos dessa maneira de se fazer pesquisa no campo de Relações Internacionais, a qual rotulam de "simplista", Mearsheimer e Walt (2013) descrevem em linhas gerais como um estudo desse tipo ocorre: em primeiro lugar, escolhe-se o fenômeno que se quer estudar, chamando-o de "variável dependente". Posteriormente, identificam-se as variáveis independentes que se julga poder explicar o fenômeno estudado, e seleciona-se data sets, grupos de dados aos quais se atribuem um valor ou indicador. Com posse dessas informações, o pesquisar pode então, seguindo uma lógica estatística, testar sua hipótese através de uma análise de regressão. O objetivo de uma pesquisa desse formato é encontrar hipóteses bem verificadas que aumentem o conhecimento acerca dos fenômenos internacionais (MEARSHEIMER \& WALT, 2013). 
$24 \mid$ InterAção

Os autores, porém, identificam diversos problemas em priorizar os testes de hipótese em detrimento da Teoria. Sua principal crítica é a de que um estudo daquele tipo não produz conhecimento útil às Relações Internacionais, levando a um estancamento do progresso da disciplina. Nesse sentido, Nau (2011) concorda que o desenvolvimento científico das Relações Internacionais depende da ampliação e da animação dos debates teóricos, levando a novas Teorias, que trariam consequências benéficas não apenas para a disciplina, mas também para a sociedade em geral. Mearsheimer e Walt (2013) ainda apontam outros problemas com os testes "simplistas": seus modelos são mal especificados, suas medições são enganosas, seus dados são fracos, sua explicação é incompleta e sua acumulação de conhecimento é insuficiente. Segundo eles, em conclusão, somente uma atenção especial à Teoria pode propiciar o devido desenvolvimento à disciplina de Relações Internacionais.

Assim como muitos dos debates teóricos e metateóricos nas Relações Internacionais, a discussão sobre o "fim das Teorias" pode nunca ter um resultado definitivo, seja em prol de um dos lados, seja na forma de uma síntese. O que se pode concluir, então, é que a teorização da disciplina passa por transformações significativas, com o surgimento, por um lado, de novas maneiras de se fazer pesquisa, e o reforço, por outro, de argumentos em favor da necessidade e da importância das Teorias. Nesse contexto, refletir acerca de conceitos, elementos basilares das teorias, sejam elas gerais ou de médio alcance, pode revelar-se essencial para elucidar pontos desse debate.

\section{GENOCÍDIO}

Alheio aos debates teóricos das Relações Internacionais, o conceito de genocídio desenvolveu-se desde o pós-Segunda Guerra Mundial. Sua definição 
25 InterAção

para o Direito Internacional advém da Convenção para a Prevenção e a Repressão do Crime de Genocídio (CPRCG), de 1948. Em seu Artigo 2 , a CPRCG conceitua-o como qualquer ato cometido "com a intenção de destruir, no todo ou em parte, um grupo nacional, étnico, racial ou religioso". Esses atos incluem o assassinato de membros do grupo, qualquer dano grave à sua integridade física ou mental, a submissão desses membros a condições de existência que proporcionem sua destruição física, total ou parcial, qualquer ato que impeça os nascimentos dentro desse grupo e a transferência forçada de menores desse grupo a outro. A Convenção ainda torna punível, através de seu Artigo $3^{\circ}$, além dos próprios atos de genocídio, a cumplicidade a eles, sua tentativa e o conluio e a incitação para cometê-los. O Estatuto de Roma do Tribunal Penal Internacional, de 1998, tem o mesmo entendimento, reproduzindo ipsis literis o Artigo $2^{\circ}$ da CPRCG ao definir, em seu Artigo 6º o crime de genocídio.

Essa definição convencional deve-se àquela dada pelo criador do termo "genocídio", Raphael Lemkin, o qual, de acordo com Jones (2006), foi responsável pelo lobby para que a ONU criasse a CPRCG, para que esta obtivesse o número necessário de assinaturas e para que os Estados a ratificassem. No ano de 1944, em sua obra O Domínio do Eixo na Europa Ocupada, Lemkin dá o nome de genocídio à "destruição de uma nação ou grupo étnico" (LEMKIN apud JONES, 2006, p. 10, tradução nossa). Ela se opera em duas fases: em primeiro lugar, ocorre a destruição dos padrões nacionais do grupo oprimido a fim de que, posteriormente, seja imposto o padrão nacional daqueles que cometem as atrocidades. Para Lemkin, pois, o genocídio é uma campanha política que visa à destruição de um grupo nacional ou étnico, mesmo que não cause a destruição física dos membros do grupo (JONES, 2006).

A definição dada por Lemkin - e, consequentemente, também aquela da CPRCG -, porém, não é pacífica entre os estudiosos de genocídio, conforme 
26 | InterAção

aponta Jones (2006). Em primeiro lugar, permanece a questão da necessidade ou não de destruição física do grupo em questão - ou seja, de mortes em massa para que seja definido um genocídio.

Uma ressonante crítica ao conceito de Lemkin também reside no foco que este dá aos grupos nacionais e étnicos, ignorando os grupos políticos. O jurista considerava que exterminar um grupo nacional ou étnico é mais grave do que exterminar um grupo político de etnia mista, tendo em vista que aquele extermínio mata toda uma cultura, que não pode ser passada adiante. A morte de indivíduos de nacionalidades diferentes, porém, não acaba com sua cultura, tendo em vista que esta pode continuar seu legado através dos membros do grupo não envolvidos no grupo político específico. Jones (2006), portanto, admite a existência de elementos "arcaicos" na definição de Lemkin:

Por um lado, significa que o assassinato de um poeta é moralmente pior do que o assassinato de um zelador, porque o poeta é o "cérebro" sem o qual o "corpo" não pode funcionar. Esse renascimento de imagens orgânicas medievais é central para a ideia de Lemkin de genocídio como um crime especial (JONES, 2006, p. 11, tradução nossa).

Assim, em meio às várias críticas a essa definição clássica de genocídio, com o desenvolvimento do campo de Estudos de Genocídio e, de maneira concreta, com a persistência do crime e seus desenvolvimentos desde a metade do século $X X$, mesmo com a existência de uma Convenção para preveni-lo e repreender, além de um tribunal internacional para puni-lo, inúmeras definições surgiram. Jones (2006) aponta que, em geral, essas definições compartilham a referência a seis elementos: os agentes, as vítimas, os objetivos, a escala, as estratégias e a intenção de um genocídio.

Como agentes, entende-se em geral o Estado e as autoridades oficiais, o que, de acordo com Evans e Newnham (1998), apresenta uma dificuldade para que se responsabilizem os criminosos responsáveis por esses atos. As vítimas, em 
$27 \mid$ InterAção

seu turno, são as minorias sociais - mas sempre em sua coletividade, ou seja, o indivíduo é alvo não por si próprio, mas por possuir determinada identidade coletiva. É relevante notar que essa identidade coletiva, suas características e critérios de pertencimento são muitas vezes definidos pelos próprios agentes. $\mathrm{O}$ objetivo do genocídio é a destruição ou erradicação de tal grupo minoritário. Salienta-se que, para que se caracterize um genocídio, não importam os motivos pelos quais se busca esse objetivo. Em termos de escala, considera-se que o ataque deve ser contra todo o grupo ou uma parte substancial dele. As definições trazem, ainda, diversas estratégias que os agentes utilizam para perpetuar o genocídio, mas considera-se que estas sempre têm o objetivo de destruir, de maneira estrutural, sistemática, deliberada e organizada. Parece aumentar o consenso acadêmico de que devam ocorrer mortes em massa, o que não é previsto, porém, pela CPRCG e por Lemkin, para os quais as execuções em massa seriam apenas uma das estratégias disponíveis aos agentes (JONES, 2006). No que diz respeito à intenção, pode-se considerar, ainda de acordo com Jones (2006), que esta só exista quando as ações são coordenadas e com o propósito claro de destruição de um grupo. Por outro lado, a intenção pode ser apenas o conhecimento ou a expectativa de que o ato perpetrado destrua, totalmente ou em parte, um grupo.

Frente ao acirrado debate sobre a conceituação de genocídio, Levene (2008) analisa cinco casos "clássicos" dessa atrocidade a fim de elaborar um "tipo ideal" do crime. O autor propõe, pois, nove atributos comuns que podem caracterizá-lo:

1. Um governo, ou regime em controle do Estado, compromissado com a extrusão de um grupo ou grupos comunais com propósitos políticos e com a capacidade logística e de recursos para empreender isso por meio do extermínio físico direto.

2. Uma ocasião na qual isso é possível com o mínimo de entraves ou interferência externa. 
28 InterAção

3. Um sentimento intensificado de crise quando isso ocorre, com o governo acreditando que há perigo extremo para si ou para o Estado.

4. Uma sequencia de mortes prolongada mas contínua através do tempo e do espaço, com o empreendimento do genocídio não reduzível a um simples ato de assassinato em massa.

5. Matança buscada independentemente de distinções de idade ou gênero.

6. O emprego de pessoal normalmente militar ou paramilitar organizado pelo Estado para liderar a matança e outros elementos da população dominante para dela participar.

7. Uma incapacidade da parte do grupo ou grupos alvo de defenderem-se ou contra-atacarem de maneira a notavelmente para ou impedir a matança.

8. Um sentimento por parte do governo de que o grupo comunal é uma ameaça genuína e séria ao bem-estar do Estado e/ou sociedade dominante de então, agora e no futuro, independentemente da coerência e da unidade coesiva do grupo enquanto grupo.

[...] O grupo alvo é o produto da montagem da realidade social do perpetrador (LEVENE, 2008, pp. 76-7, 86, tradução nossa).

O autor problematiza, assim, o conceito de genocídio de uma maneira deveras complexa, que vai além da definição adotada pelo Direito Internacional - aquela apresentada pelo Artigo $2^{\circ}$ da CPRGC e reproduzida no Estatuto de Roma, Artigo 6 ${ }^{\circ}$. O mesmo faz Hannah Arendt (1999; 2010), cujo pensamento adiciona à discussão a consideração do genocídio como um crime contra a condição humana, caracterizada, entre outros, pela pluralidade:

Com efeito, a possibilidade e a intencionalidade de exterminar grupos étnicos, nacionais, religiosos ou raciais - [...] vale dizer, a aspiração de fazer desaparecer da face da terra um grupo, antes de ser um delito que fere os direitos das minorias é um crime contra a humanidade e a ordem internacional [...] porque visa eliminar a diversidade e a pluralidade que caracterizam o gênero humano [...] (LAFER, 1988, p. 183).

Ademais, o Holocausto, segundo Arendt (1999), não ocorreu por conta de um mal radical que tomou conta da Alemanha nazista, mas, pelo contrário, pela banalização desse mal, o qual se tornou legalizado e burocratizado - insere-se, 
29 | InterAção

pois, no contexto da gestão política totalitária do Estado (LAFER, 1988). A análise arendtiana, assim como a de Levene (2008) revelam, portanto, que o genocídio não é um fenômeno que deve ser pensado apenas sob o viés jurídico. Suas conceituações e tipificações incluem elementos filosóficos e de Ciência Política, mas os Estudos de Genocídio ainda tem influências advindas da Psicologia, da Sociologia, da Antropologia, entre outros. Para que haja de fato uma compreensão completa do que significa genocídio, pois, é necessário que se transcenda uma discussão restrita ao Direito. Pergunta-se, nesse contexto, se as Relações Internacionais podem trazer alguma contribuição a essa conceituação; em caso afirmativo, qual? A seguir, argumenta-se que essa contribuição pode ser rica e relevante.

\section{GENOCÍDIO E RELAÇÕES INTERNACIONAIS}

Levando em consideração as supracitadas análises que transcendem a discussão jurídica sobre essa atrocidade, o desenvolvimento de um campo de "Estudos de Genocídio" levou a pesquisa sobre tal tema a abarcar, como se afirmou, diversas disciplinas: a Psicologia Social, a Antropologia, a Sociologia, a Filosofia, a Ciência Política são alguns exemplos. A expansão da preocupação acerca do assunto, aliada aos debates que ainda acontecem nas Relações Internacionais sobre a delimitação de seu campo de pesquisa levam a perguntarse, pois, se também a essa disciplina concerne o estudo dos casos de genocídio.

Considerando que, lato sensu, Relações Internacionais é o estudo dos fenômenos transfronteiriços, a ponderação anterior traduz-se no questionamento da característica de o genocídio ser um fenômeno que atravesse ou transcenda as fronteiras. A dúvida é pertinente tendo em vista que, conforme o "tipo ideal" 
30 InterAção

elaborado por Levene (2008), é geralmente o governo ou alguém agindo em seu nome que se torna o agente do genocídio, vitimando grupos dentro de seu próprio Estado. O fenômeno, assim, estaria restrito àquele país e seria mais pertinente analisá-lo, pois, através da ótica da Ciência Política da relação do Estado com os cidadãos, por exemplo.

Argumenta-se, porém, que o genocídio é um fenômeno que deve, de fato, ser estudado pela disciplina de Relações Internacionais, tendo em vista seus impactos não restritos ao próprio local onde acontecem as atrocidades. Um exemplo é a grande fluxo de refugiados que se deslocam aos países vizinhos àquele onde acontece o genocídio. O caso da região de Darfur, por exemplo, foi levado à atenção do Conselho de Segurança das Nações Unidas apenas quando se percebeu o grande número de sudaneses que entravam no território do Chade fugindo da perseguição do governo central e da milícia Janjaweed, apoiada por ele. Em outro sentido do fluxo migratório, Midlarsky (2005) conclui que a entrada de refugiados judeus na Alemanha foi uma das causas do Holocausto.

O genocídio é um fenômeno que transcende as fronteiras também pela discussão acerca da maneira mais efetiva de combatê-lo. Apesar de debates e controvérsias, muitos autores concordam que as intervenções humanitárias internacionais são formas legítimas de se interromper um transcorrente caso de genocídio. Bellamy (2010), por exemplo, argumenta que os genocídios podem acabar apenas de duas formas: ou com o êxito da missão dos genocidas, erradicando o grupo a que se propõe exterminar; ou com sua derrota militar. Ele afirma, portanto, que há uma obrigação moral de intervir, desde que a ação não cause mais danos do que benesses. Jones (2006), por outro lado, alerta para os perigos de uma intervenção, que pode dar ainda mais poder a países já poderosos para impor seus ditames aos mais fracos. Apesar de exaltar as virtudes de intervenções regionais, que sofreriam de menos problemas de logística e teriam 
31 InterAção

mais afinidades étnico-culturais com o país no qual acontecem, o autor alega que os interesses por detrás da atuação do interventor nunca são apenas humanitários, podendo esconder inclusive a possibilidade de uma “ambição imperial" (JONES, 2006, p. 395, tradução nossa). Em conclusão, caso haja uma intervenção internacional visando cessar as atrocidades advindas de um genocídio, deve-se sempre proceder com prudência e cautela, visando a gerar mais benefícios do que criar problemas para uma população já fortemente debilitada por ser vítima de um crime atroz.

O genocídio insere-se, portanto, nas Relações Internacionais através de transformações na agenda internacional que ocorreram após a Guerra Fria. As preocupações majoritárias com segurança estatal decaíram depois do fim da disputa entre Estados Unidos e União Soviética, dando lugar a novos temas como a proteção ambiental, o desenvolvimento e a segurança humana, através do conceito de Responsabilidade de Proteger (R2P). Assim, questões humanitárias como crimes de guerra, genocídio e demais crimes contra a humanidade merecem a atenção das Relações Internacionais por fazerem parte dessa nova agenda.

\section{GENOCÍDIO E O DEBATE SOBRE 0 “FIM DA TEORIA”}

Concluindo-se que o genocídio é, de fato, um tema relevante para a disciplina de Relações Internacionais, pode-se, pois, indagar se o caminho mais adequado para o desenvolvimento de estudos sobre esse tema, no contexto do debate do "fim da teoria", é através do desenvolvimento e teste de hipóteses, ou da inserção do conceito em uma Teoria mais geral. 
32 InterAção

Cada caso de genocídio tem suas especificidades e, portanto, a presunção de universalismo das Teorias pode ser considerada um fator que indica que os casos desse crime devem ser estudados de maneira mais particular. Além disso, ainda não se desenvolveu uma teoria coesa de médio alcance que explique o fenômeno "genocídio" e, assim, os testes de hipótese podem ser inestimáveis para que o campo de "Estudos de Genocídio" tenha uma teoria própria. Pode-se alegar, ainda, que os genocídios são fenômenos extremamente raros no sistema internacional e que, portanto, não são relevantes para uma explicação universal de seu funcionamento.

Mesmo em face desses argumentos em prol de um estudo do conceito através de testes de hipótese, defender-se-á, porém, neste trabalho, que o objetivo do estudo de casos de genocídio no campo das Relações Internacionais, além da forma pelo qual ele deve ser trabalhado, é mais afim à inserção desse conceito em Teorias mais gerais. Desenvolver-se-á três argumentos para a sustentação dessa opinião: um substantivo, um normativo e um metodológico.

Substantivamente, o tipo ideal proposto por Levene (2008) revela a ligação estreita entre os casos de genocídio e a atuação Estatal. É um conceito, portanto, que cabe em uma Teoria de Relações Internacionais, cujas unidades de análise são, em geral, os Estados. Apesar de o Realismo, por exemplo, considerá-lo um ator unitário, analisar o uso da violência extremada por um Estado, por mais raro que seja (pelo menos sob a forma de genocídio), ajuda a elucidar o comportamento do governo, além de suas clivagens internas e disputas por poder, em Teorias que não se utilizam do modelo realista de "bolas de bilhar".

Autores realistas podem encontrar em casos de genocídio, mesmo que a matança não cruze qualquer fronteira, causas de tensões entre Estados vizinhos, ou reflexos da balança de poder nas iniciativas de intervenções humanitárias. Já Teorias liberais podem-se utilizar de genocídios como casos desviantes à 
33 | InterAção

propagação da democracia e das liberdades civis mais básicas. Análises construtivistas enquadram-se perfeitamente na análise da criação identitária dos grupos que se hostilizam e das percepções de eu e de outro durante massacres étnicos ou religiosos. Estudar os genocídios para entender os próprios genocídios é uma atividade relevante, certamente, mas ignora, portanto, um potencial vigoroso que esse fenômeno tem de revelar padrões bem mais gerais do funcionamento do sistema internacional e de seu principal ator, o Estado.

Não apenas os estudos sobre genocídios podem revelar tendências mais amplas da atuação estatal no sistema internacional, as Teorias, cujo objetivo é explicar todos os fenômenos que nele ocorrem, também devem procurar elucidar esses casos. Assim, a pesquisa de genocídio através de Teorias ajuda a fortalecer elas próprias, adequando seus pressupostos à ocorrência desses casos, mesmo e especialmente porque - raros. A teorização sobre todos os outros aspectos das relações internacionais, portanto, também se torna mais vigorosa através da teorização acerca desse conceito específico.

O segundo argumento é normativo, e diz respeito aos “Estudos de Genocídio" enquanto campo. Essa disciplina, mesmo incipiente, tem objetivos claros: deter genocídios que estejam ocorrendo no globo, e, principalmente, prevenir que novos casos eclodam. O teste de hipóteses certamente pode revelar padrões do fenômeno genocídio, determinar indícios de potenciais novos casos e demonstrar como funcionam os mecanismos que dão fim aos genocídios que acabam ocorrendo. Porém, as Teorias têm uma capacidade previsível - mesmo que dentro dos limites advindos do fato de seus objetos de estudo serem fenômenos complexos e largamente indefinidos - ainda maior, ao revelar tendências mais gerais de comportamento dos atores. Ao se incluir o conceito "genocídio" nas Teorias de Relações Internacionais, o associando a padrões mais amplos de atuação internacional, o alerta a possíveis casos pode ser mais 
$34 \mid$ InterAção

prematuro do que se os indícios procurados para se realizar a prevenção fossem aqueles advindos de uma análise de hipótese, preocupada apenas com os mecanismos causais do genocídio e que inclui variáveis, portanto, verificadas apenas em um estágio no qual já é tarde demais para detê-lo.

Além da capacidade de predição, outra característica das Teorias apontada por Mearsheimer e Walt (2013) que as tornam mais adequadas ao estudo do fenômeno em questão é sua capacidade de diagnosticar problemas políticos e auxiliar nas decisões, também ajudando na avaliação das políticas adotadas. Essa análise é deveras importante em casos de genocídio, tendo em vista que as políticas preventivas e combativas a esse problema têm sido, em geral, falhas, seja internamente nos Estados onde ocorre, seja por intervenção de outros atores internacionais. Conforme se afirmou, tem-se tentando impedir os genocídios através de intervenções humanitárias - e a possibilidade de proposição e avaliação de políticas é essencial para se concluir, de fato, se esse é o meio mais adequado de fazê-lo e para propor alternativas construtivas.

Por fim, o terceiro argumento é metodológico, e encontra-se estreitamente relacionado ao argumento normativo anteriormente discutido. Coeditor do Journal of Genocide Research, Huttenbach (2000) defende que genocídios devem ser estudados comparativamente, porque "para determinar a essência do genocídio [...] deve-se poder encontrar um denominador comum que une todos os genocídios, não importa quando, onde ou como eles ocorreram" (HUTTENBACH, 2000, p. 2, tradução nossa). O clamor do estudioso parece ser justamente por uma teoria de médio alcance, específica sobre genocídio, desenvolvida através de testes de hipótese com desenhos de pesquisa como o de "maior semelhança" ou "maior diferença", por exemplo. Porém, levando-se em consideração os objetivos normativos da disciplina, citados acima, apesar da relevância desse tipo de estudo, o objeto de pesquisa "genocídio" requer uma 
35 | InterAção

generalização maior, um nível de abstração que permita a previsão e solução de casos tão distintos e complexos.

Alia-se a esse fator a dificuldade que têm, conforme apontam Mearsheimer e Walt (2013), os testes de hipótese de medir adequadamente os fenômenos. O genocídio é exemplo claro desse argumento dos autores. Um desenho de pesquisa comparativo nos moldes requeridos pelo estudo através do teste de hipóteses tem a necessidade de variáveis muito precisas, com indicadores claros e valores bem definidos. Não é o caso em fenômenos como o que está aqui em questão. Há muita dificuldade em estabelecer quais as variáveis responsáveis por um genocídio, quais os indicadores para essas variáveis, e quais valores devem eles assumir. O estudo através das Teorias, portanto, poderia levar a uma ponderação mais aberta e flexível nesse sentido, em um estágio de pesquisa sobre esse objeto no qual todos esses elementos metodológicos ainda não estão bem claros em muitos de seus raros casos.

Através dos argumentos enumerados acima, pode-se concluir que o campo de "Estudos de Genocídio" é ainda bastante incipiente. O estudo de seu objeto de pesquisa, no que concernem suas implicações transfronteiriças, ou seja, à disciplina de Relações Internacionais, seria bastante beneficiado pela tentativa de se fazerem estudos teóricos, relacionando o conceito às Teorias. Não apenas esse formato permitiria melhor previsão e normatividade política, auxiliando assim o campo a atingir seu objetivo primordial de prevenção e combate a esse crime contra a humanidade, mas também impulsionaria um desenvolvimento inicial relevante aos estudos sobre o genocídio, revelando, por exemplo, hipóteses e variáveis que poderiam, então, ser testadas, dando origem a uma teoria mais específica, de médio alcance, acerca desse objeto. 
36 | InterAção

\section{CONSIDERAÇÕES FINAIS}

Não se pretendeu, com este artigo, desqualificar o estudo do genocídio, ou mesmo das relações internacionais em geral, através do teste de hipóteses cujo objetivo é o desenvolvimento de teorias de médio alcance, e não Teorias Gerais. O que se buscou argumentar é que, no estágio atual de pesquisa acerca desse objeto, e dados os objetivos do campo nascente denominado "Estudos de Genocídio", a tentativa de inserir o conceito de genocídio em um arcabouço teórico mais amplo é de extrema relevância e pode revelar-se deveras produtivo.

Não se vislumbra, pelo menos neste momento de desenvolvimento do campo das Relações Internacionais, um final ou síntese ao debate sobre o "fim da teoria". Tanto o teste de hipótese de mecanismos causais quanto à elaboração de grandes Teorias trazem contribuições importantes ao desenvolvimento científico, e saber trabalhar com essas duas ferramentas complementarmente é um trunfo para o pesquisador. Reitera-se, ademais, que essas formas de pesquisar não são mutuamente excludentes, mesmo quando se estudando um mesmo objeto de pesquisa.

O genocídio apresenta-se como o mais atroz crime contra a humanidade, propagando-se mesmo no "evoluído" século XXI. Estudá-lo, compreende-lo, discuti-lo, mostram-se tarefas essenciais para se ter êxito em sua prevenção e erradicação. Assim, a lição ao estudioso desse fenômeno é a de que não pode descartar nenhuma ferramenta analítica, nenhuma relação com qualquer campo de pesquisa, por mais diverso que seja - e quanto mais diverso, melhor, para tornar a análise mais robusta -, a fim de que seus perpetradores não permaneçam impunes e suas vítimas não continuem sofrendo. 
37 InterAção

\section{REFERÊNCIAS}

ARENDT, Hannah. Eichmann em Jerusalém: um relato sobre a banalidade do mal. São Paulo: Companhia das Letras, 1999.

A condição humana. 11 ${ }^{\mathrm{a}}$ ed. revista. Rio de Janeiro: Forense, 2010.

BELLAMY, Alex J. Military intervention. In: BLOXAM, D.; MOSES, A. The Oxford handbook of genocide studies. Oxford: Oxford University Press, 2010, pp. 597-616.

BENNET, Andrew. The mother of all isms: causal mechanisms and structured pluralism in International Relations theory. European Journal of International Relations. 2013, 19: 459.

DUNNE, Tim; HANSEN, Lene; WIGHT, Colin. The end of International Relations theory? European Journal of International Relations. 2013, 19: 405.

EPSTEIN, Charlotte. Constructivism or the eternal return of universals in International Relations. European Journal of International Relations. 2013, 19 : 499 .

EVANS, Graham \& NEWNHAM, Jeffrey. Dictionary of International Relations. Londres: Penguin Books, 1998.

HUTTENBACH, Henry R. Note from the editor: no comparing, no thinking the unavoidable future of studying genocide. Journal of Genocide Studies, vol. 2, n. 3, 2000, pp. 2-3.

JONES, Adam. Genocide: a comprehensive introduction. Londres e Nova York: Routledge, 2006.

LAFER, Celso. A ruptura totalitária e a reconstrução dos direitos humanos: um diálogo com Hannah Arendt. São Paulo, 1988.

LAKE, David. Why "isms" are evil: theory, epistemology, and academic sects as impediments to understanding and progress. International Studies Quarterly. 2011, 55: 465-80.

MEARSHEIMER, John; WALT, Stephen. Leaving theory behind: why simplistic hypothesis testing is bad for International Relations. European Journal of International Relations. 2013, 19: 427. 
38 | InterAção

MIDLARSKY, Manus I. The demographics of genocide: refugees and territorial loss in the mass murder of European Jewry. In: Journal of Peace Research, vol. 42, n. 4, 2005, pp. 375-391.

NAU, Henry R. No alternative to “isms". International Studies Quarterly. 2011, 55: 287-91. 